\title{
Chapter 8 \\ Science-Policy Interfaces in Baltic Sea \\ Environmental Governance: Towards \\ Regional Cooperation and Management \\ of Uncertainty?
}

\author{
Sebastian Linke, Michael Gilek, and Mikael Karlsson
}

\begin{abstract}
This chapter investigates and compares the interactions between science and policy (risk assessments and risk management) in five cases of environmental governance of the Baltic Sea: eutrophication, fisheries, invasive alien species, chemical pollution and oil discharges. An efficient interplay between science and policy is important for successful environmental governance, which applies particularly to the Baltic Sea where all five risks pose serious threats to environmental, social and economic aspects of sustainability. We use science-policy theory and an analytical framework based on a categorisation of relevant management responses linked to different states of incomplete knowledge (risk, uncertainty, ambiguity, ignorance) to investigate two main characteristics of science-policy interfaces: (1) organisational structures and (2) procedural aspects of managing scientific uncertainties and stakeholder disagreements. The analyses reveal differences and similarities in institutional and organisational designs of the respective assessment-management interactions, as well as in terms of how scientific uncertainties, stakeholder disagreements and sociopolitical ambiguities are addressed. All the five science-policy interfaces expose science-based management approaches that commonly are not able to cope sufficiently well with the complexities, uncertainties and ambiguities at hand. Based on our cross-case analyses, we conclude by recommending five key aspects that need
\end{abstract}

\footnotetext{
S. Linke $(\bowtie)$

Department of Philosophy, Linguistics and Theory of Science, University of Gothenburg, Box 200, 40530 Göteborg, Sweden

e-mail: sebastian.linke@gu.se

M. Gilek • M. Karlsson

School of Natural Sciences, Technology and Environmental Studies, Södertörn University, 14189 Huddinge, Sweden

e-mail: michael.gilek@sh.se; mikael.karlsson@2050.se
} 
to be addressed to improve science-policy interactions in Baltic Sea environmental governance: ( 1 ) more adaptive organisational structures in terms of time, context and place dependency, (2) increased knowledge integrations, (3) a more careful consideration of stakeholder participation and deliberation, (4) better management of uncertainty and disagreements and (5) increased transparency and reflection in the communication of science-policy processes.

Keywords Science-policy interactions - Marine policy $\bullet$ Post-normal science $\bullet$ Uncertainty management $\bullet$ Stakeholder participation

\subsection{Introduction}

The five cases of environmental governance studied in this project have been identified as key large-scale environmental problems and risks in the Baltic Sea (see Gilek et al. 2016; HELCOM 2010): fisheries, eutrophication, invasive alien species, chemical pollution and oil discharges linked to marine transportation. However, as revealed throughout the previous chapters, they differ substantially in terms of the complexity of risk sources, the available knowledge and the uncertainties connected to assessing environmental effects for advising decision-making, as well as with respect to the degrees of ambiguity and sociopolitical controversy involved in policy and management (Gilek et al. 2011).

In this chapter, we investigate the interactions between risk assessment (science) and risk management (policy) in the five different cases. We analyse and compare these interactions using a theoretical framework on science-policy interfaces described in Sect. 8.2. Specifically, we study how organisational structures and processes of science-policy interactions adapt to key challenges of science and management in environmental governance by focusing on different forms of uncertainty, as well as on stakeholder conflicts and disagreements involved in science and/versus policy in the five cases. We also trace the respective management reactions to these challenges in each of the cases using a typology of different kinds of incomplete knowledge and their consequences for management responses as described below (Sect. 8.2.2). Through this comparative study of science-policy interfaces across the five cases, we point out institutional and procedural hindrances, challenges and prospects for improving science-policy interactions for a more effective and sustainable environmental governance of the Baltic Sea. Following the discussion on our theoretical framework, we present the results of our analysis of the five science-policy interfaces (Sect. 8.3). The two sections thereafter discuss the outcomes of the study (Sect. 8.4) and provide conclusions and recommendations (Sect. $8.5)$, respectively. 


\subsection{Theoretical Context}

\subsubsection{Science-Policy Theory and the Ecosystem Approach to Management}

Science-based advice is universally regarded and used as a primary trustworthy basis for environmental management and decision-making. However, at the same time, in many areas, there is an ambiguity and increasing concern about the sole dependence on expertise from the (natural) sciences, which often acts to the detriment of sufficient consideration of other knowledge claims, stakeholder perspectives and values held by actors such as NGOs, citizens or business people. Bijker et al. (2009: 1) have called this phenomenon the paradox of scientific authority and asked the question of "how can scientific advice be effective and influential in an age in which the status of science and/or scientists seems to be as low as it has ever been?' One reason for this paradox lies in the fact that science becomes politicised whenever it is called into a political context (Weingart 1999) and is hence subject to constraints, i.e. rules, norms and evaluation criteria, other than those set by the scientific community. A basic challenge is that the demarcation that exists between the spheres of science and politics falls apart in such contexts, which consequently leads to concerns and potential conflicts about the legitimate role of science and its relation to policy. Both the role of science-based advice and the political decisions based on it may therefore become contested with respect to credibility, legitimacy and accountability (cf. Cash et al. 2003).

In management practice, a distinction is often made between a science system (representing factual knowledge claims) and a social system (representing political, business and other concerns of public life) - a division that is inscribed in the institutional design of most policy systems in modern societies. Science is responsible for providing the best available knowledge in terms of a presumed value-free and objective input to political decision-making, which is accordingly seen as most rational and democratically legitimated (Funtowicz and Strand 2007; Wilson 2009). This idealised model of interaction between science and policy relies on what has been called the 'ideal causal chain' of implementing scientific knowledge in policy processes (Fig. 8.1; Gezelius 2008).

The ecosystem approach to management (EAM) is seen as a necessary and idealistic approach for managing marine resources and other environmental issues with regard to all five areas of environment and risks analysed here (Backer et al. 2010; Garcia et al. 2003; Hammer 2015). As a consequence, assessment and management

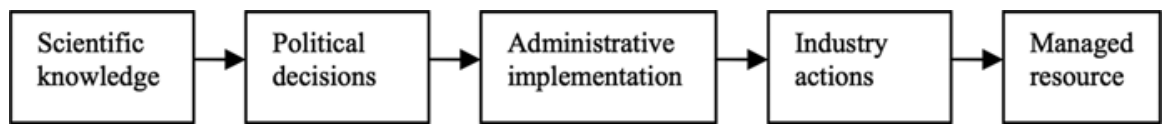

Fig. 8.1 The 'ideal causal chain' model of science input to management as, for example, described for EU fisheries by Gezelius (2008) (Reprinted with permission of Springer) 
practices need to adapt to new ways of giving, using and implementing various sorts of advice. This shift towards EAM is furthermore in line with the EU's general principles of 'good governance' (COM 2001: 10) applied in various marine policies such as the Common Fisheries Policy (CFP), aiming for a 'broad involvement of stakeholders at all stages of the policy from conception to implementation' (EC 2002: 6).

Our study analyses the problems and challenges faced when a traditional conceptualisation of science-policy interfaces, such as the 'ideal causal chain' model, is applied to different cases of environmental governance in the Baltic Sea and suggests ways in which associated problems and challenges might be countered. Applying the EAM concept, with its aspirations to achieve sustainable use of ecosystems in line with place-based requirements and sensitivities of the socioecological system (cf. Boström et al. 2016), opens new opportunities for a more holistic approach to understand and design science-policy interfaces by taking both the natural system (represented via science) and the social system (sociopolitical aspects) into account (cf. Gilek et al. 2015). The widening perspective of EAM could hence contribute to avoiding some of the traditional pitfalls of narrowly assigned science-based management systems. One of these pitfalls is the strongly sector-based marine environmental governance of the Baltic Sea that is studied here.

Furthermore, all our case studies present strongly politicised domains of environmental governance (albeit with case-specific differences), where the boundaries between science and policy are continuously blurred and often debated. This implies that political and cultural values heavily influence scientific processes while science on the other hand strongly influences policy developments. This phenomenon is described as the 'co-production of science and policy' (Jasanoff 2004; Jasanoff and Wynne 1998) and highlights key questions about the roles and responsibilities of different actors such as scientists (and the science system) and other relevant stakeholders and policymakers in the interplay between assessment and management. In this 'co-produced' context, new and developed institutional structures and processes of interaction could act as 'boundary organisations' between science and policy that make environmental problems governable. As Lidskog (2014:3) states: 'By negotiating and renegotiating the boundaries between science and policy, environmental problems and their possible solutions are co-produced. Both science and policy are mobilised in order to solve a specific environmental problem'.

\subsubsection{Analytical Framework and Methods}

EAM emphasises the importance of two major aspects of environmental governance. It first highlights a regional basis for management. Second, it emphasises appropriate processes, methods and techniques for dealing with uncertainties and disagreements in the interaction between science and policymaking. Using an analytical framework focussing on science-policy interactions as outlined below, 
we investigate how these two aspects are dealt with in the five cases of environmental governance in the Baltic Sea.

Emphasising the importance of organisational structures and procedural interactions of the science-policy interface highlights if and how the challenges connected with assessment-management interactions differ between the five cases analysed in this study (as seen, e.g., when comparing fisheries and eutrophication cf. Karlsson et al. 2016; Linke et al. 2014; Sellke et al. 2016). Stirling (2010: 1029) has argued with regard to the neglect of such relevant differences that an 'overly narrow focus on risk is an inadequate response to incomplete knowledge', because it makes the (necessarily simplified) science-based advice vulnerable to social interests, political manipulation and pressures from lobby groups. Stirling therefore suggests an 'opening up' of linear, scientific conceptions of the science-policy interface for more plural and situated understandings (Stirling 2008: 262). He also suggests it is necessary to take a more careful account of the nature of the knowledge at hand by saying that "when the intrinsically plural, conditional nature of knowledge is recognised, I believe that science advice can become more rigorous, robust and democratically accountable' (Stirling 2010: 1029). In order to better adapt sciencepolicy interactions to these insights, he has developed an 'uncertainty matrix' that differentiates between four different idealised states of incomplete knowledge (Fig. 8.2).

The formal state of risk (Fig. 8.2) is characterised by a comparatively high level of confidence in both the knowledge about possible outcomes as well as about their respective probabilities. It can thus be handled by traditional linear risk assessmentmanagement procedures based on a straightforwardly applied scientific approach (as in Fig. 8.1). However, this is not the case in the three other cases of the matrix, namely, uncertainty, ambiguity and ignorance, which according to Stirling differ from the traditional risk categorisation.

Under the condition of scientific uncertainty, it is still feasible to characterise possible outcomes but the available information input (data) is too incomplete to assign specific probabilities (e.g. as often is argued for the enormous number of chemical pollutants in the environment). For such (uncertain) environmental issues, as Stirling (2007: 310) notes, 'the scientifically rigorous approach is therefore to acknowledge various possible interpretations'.

The condition of ambiguity is, on the other hand, not primarily characterised by problematic knowledge about probabilities (data input) but about the possible outcomes and contested interpretations and framings of the environmental issue. The management of various marine resources, such as commercial fish stocks, has been argued to belong to this type of an environmental issue (cf. Linke et al. 2014). For such cases, disagreements among disciplines and specialists may arise as a consequence of different integration of ecological, agronomic, safety or socio-economic criteria of harm. Therefore, the application of a traditional natural science-based assessment alone is neither rigorous nor rational (Stirling 2007) and needs to be complemented with social science-based 'concern appraisals' (Renn 2008).

Finally, the condition of ignorance is one where neither the knowledge about probabilities nor about outcomes can be made fully clear (as argued to be the case 


\begin{tabular}{|c|c|c|}
\hline 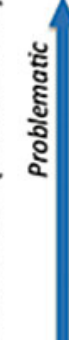 & $\begin{array}{l}\text { AMBIGUITY } \\
\text { - Contested framings, } \\
\text { questions, methods } \\
\text { - No expert consensus } \\
\text { - Natural \& social } \\
\text { assessments } \\
\text { (interdisciplinarity) }\end{array}$ & $\begin{array}{l}\text { IGNORANCE } \\
\text { - Unanticipated effects } \\
\text { - Unexpected conditions } \\
\text { - Gaps, surprises, } \\
\text { unknowns } \\
\text { - Novel agents like e.g. } \\
\text { invasive species }\end{array}$ \\
\hline 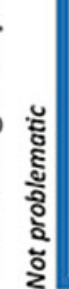 & $\begin{array}{l}\text { RISK } \\
\text { - Familiar systems } \\
\text { - Controllable conditions } \\
\text { - Expert consensus } \\
\text { - Cost-benefit analysis } \\
\text { - E.g. transport safety }\end{array}$ & $\begin{array}{l}\text { UNCERTAINTY } \\
\text { - Complex, nonlinear, } \\
\text { open systems } \\
\text { - Data limitations } \\
\text { - Unpredictable, un- } \\
\text { assessed outcomes }\end{array}$ \\
\hline \multicolumn{3}{|c|}{ Not problematic Knowledge about probabilities ${ }^{\text {Problematic }}$} \\
\hline 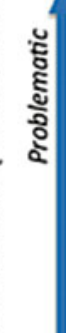 & $\begin{array}{l}\text { AMBIGUITY } \\
\text { - Stakeholder } \\
\text { participation } \\
\text { - Deliberation, } \\
\text { negotiation } \\
\text { - Interactive modeling } \\
\text { - Multi-criteria mapping }\end{array}$ & $\begin{array}{l}\text { IGNORANCE } \\
\text { - Open-ended monitoring } 8 \\
\text { surveillance } \\
\text { - Flexibility, adaptability, } \\
\text { resilience, robustness } \\
\text { - Transdisciplinarity \& } \\
\text { institutional learning }\end{array}$ \\
\hline & $\begin{array}{l}\text { RISK } \\
\text { - Classic risk assessment- } \\
\text { management processes } \\
\text { - Science-based advice } \\
\text { - Cost-benefit decision } \\
\text { analysis }\end{array}$ & $\begin{array}{l}\text { UNCERTAINTY } \\
\text { - Burden of evidence } \\
\text { - Uncertainty factors } \\
\text { - Scenario methods } \\
\text { - Sensitivity intervals } \\
\text { - Evaluative judgments }\end{array}$ \\
\hline
\end{tabular}

Fig. 8.2 A categorisation of four different states of incomplete knowledge (above) and possible responses to them for management procedures (below); based on Stirling (2010), see text for explanation

for invasive alien species, see Smolarz et al. 2016). Such environmental problems and risks differ from issues characterised by uncertainty in that outcome parameters cannot be pinpointed and agreed upon. Such cases also differ from environmental issues characterised by ambiguity in that knowledge about probabilities is not only contested but, often, simply unknown (Stirling 2007). 
Stirling's approach to discern different types of incomplete knowledge, with regard to scientific uncertainty and sociopolitical ambiguity, has also been addressed, for example, through the concept of post-normal science (PNS) as put forward by Funtowicz and Ravetz (1993). Similar to Stirling's notion of 'ignorance', the concept of PNS proposes that under conditions of high uncertainty (limited knowledge on probabilities) and high social stakes (limited knowledge on possible outcomes), management responses to environmental problems need to seek solutions not only based on input from science, as evaluated by traditional peer review, but assembled also in an open dialogue with all affected stakeholders, something the authors call 'extended peer communities' (ibid.). These extended peer communities serve to employ additional information, knowledge and values for an active, more effective and legitimate process to identify possible solutions to specific environmental problems.

Following this classification of different forms of incomplete knowledge, Stirling also proposes a number of methodological responses that should 'illustrate the rich variety of alternatives that exist if risk assessment is not properly applicable' (Stirling 2007: 312; Fig. 8.2). However, such alternative approaches should not be taken as a 'neat one-to-one mapping of specific methods to individual states of knowledge' (ibid.) but rather serve as an array of more adequate reactions to different types of uncertainty problems that complement (and not necessarily substitute for) the traditional risk assessment-based approach.

The different categories of science-policy interactions summarised in Fig. 8.2 illustrate a more diversified picture than the 'ideal causal chain' model of applying only a traditional scientific definition of environmental problems in a linear fashion to management processes (Fig. 8.1). While traditional scientific assessment and science-based management offer powerful tools under the condition of risk (comparatively low uncertainty and known outcomes), this approach is not solely applicable to the other three categories identified by high levels of uncertainty, ambiguity and ignorance. However, contrary to such insights, the traditional scientific approach to only apply the best available (natural) scientific knowledge to policy- and decision-making often prevails and causes problems and controversy. As Stirling notes, 'persistent adherence to these reductive methods, under conditions other than the strict state of risk, are irrational, unscientific and potentially misleading' (Stirling 2007: 311).

Following this line of reasoning, we investigate whether and how different roles and approaches of science-based advice and adaptations to them in the form of management responses have evolved in our five cases of environmental governance in accordance with Stirling's typology. After analysing science-policy interfaces of the five cases in the following section, we will comparatively discuss the appropriateness of the different approaches to science and policymaking with respect to different forms of incomplete knowledge and draw conclusions on how to deal with the discovered science-policy challenges.

With respect to the theoretical context described above, our analysis focuses on two sets of questions to investigate assessment-management (science-policy) interactions in the five cases, linked to the implementation of EAM: 
1. Organisational structures (institutional design) of the risk assessment activities and the generation, selection and implementation of management options

2. The management of scientific uncertainties and stakeholder disagreements

Under organisational structures, we are concerned with the institutional interfaces between risk assessment and management activities. We therefore analyse the regional (Baltic Sea) basis of science-policy cooperation in the five cases asking the following questions: who is performing the assessment activities and how are assessment activities organised and carried out in committees, etc.?

With regard to the second point, the management of scientific uncertainties and stakeholder disagreements, we investigate the science-policy interfaces with respect to how actual procedures of assessment activities are linked to the processes of giving advice and how management and decision-making bodies deal with different states of (often incomplete) knowledge and information from various sources and sectors. We also examine how stakeholder participation, knowledge inclusion and deliberation procedures are implemented.

By using this analytical framework we aim to achieve a better understanding of how governance arrangements and processes linked to various environmental problems and risks can deal effectively with the challenges of incomplete knowledge, uncertainty and stakeholder disagreements. We finally give a number of recommendations about how to possibly redesign institutional and procedural structures of science-policy interactions more effectively in the five cases of environmental governance as this will be of value also to other complex cases of environmental governance.

Methodologically, the analyses informing this chapter are based on empirical research conducted for the five case studies of the RISKGOV project, ${ }^{1}$ which are described in the first part of this volume (Hassler 2016; Karlsson and Gilek 2016; Karlsson et al. 2016; Sellke et al. 2016; Smolarz et al. 2016). The case studies analysed the five marine environmental governance issues mentioned above with respect to three governance dimensions (see Gilek et al. 2016), one of which was 'assessment-management processes and interactions' which informed the metaanalysis presented in this chapter. For comparative purposes, the case studies used a common analytical framework and similar methodological research design (for a description, see Gilek et al. 2016; cf. Gilek et al. 2011). The results of the case studies are derived from three main data sources: document studies, semi-structured qualitative interviews (ca. 15 per case) as well as three joint thematic round-table discussions. This extensive empirical material, in combination with other research on science-policy interactions in different fields of environmental governance (see, e.g., Linke et al. 2014; Gilek et al. 2015), forms the background for the analyses presented in this chapter and allows us to draw conclusions and give recommendations for improving science-policy interactions for environmental governance of the Baltic Sea.

${ }^{1}$ Environmental Risk Governance of the Baltic Sea (2009-2015). See www.sh.se/riskgov 


\subsection{Results}

\subsubsection{Organisational Structures of Science-Policy Interfaces}

\subsubsection{Fisheries}

Fisheries management in the Baltic Sea is primarily governed by the EU through the Common Fisheries Policy (CFP). The EU involves all member states around the Baltic Sea except Russia (see Sellke et al. 2016). The CFP connects the scientific assessments of fish stocks, executed on a regional basis (i.e. the Baltic Sea) by the International Council for the Exploration of the Sea (ICES), with management decisions taken by the EU troika of the commission, the council of ministers and the parliament. ICES works primarily for its main client, the EU Commission, and formulates requested annual scientific advice based on single fish stock assessments. Hence, regional cooperation with other management bodies such as HELCOM is rather weak and underdeveloped (Linke et al. 2014). Due to its centralised science-based structure, EU fisheries management has been depicted as 'perhaps the most top-down fisheries management system on the planet' (Degnbol and Wilson 2008: 189) and 'perhaps the most science-dependent sector in the EU' (Griffin 2009: 563). A strong dependency between science (in the form of annual fish stock assessments and subsequent fishing advice) and policy (in the form of management regulations mainly using fishing quotas) was established in modern fisheries management in the North Atlantic during the 1960s and 1970s (Gezelius 2008) and later applied to the Baltic Sea with the establishment of the CFP and an incremental EU enlargement. The institutionalised dependence between science and policy has been described as the 'TAC machine' (Nielsen and Holm 2008), which suggests that the annual single fish stock approach to management is largely incompatible with more holistic environmental governance concepts like multispecies management or EAM (Wilson 2009).

Two recent reforms of the CFP, conducted in 2002 and 2013, have aimed to change the policy system so that there is increased involvement of stakeholders in fisheries management, as well as more regionalisation on a sea-basin level, including the Baltic Sea region (Sellke et al. 2016). The 2002 CFP reform resulted in a new type of stakeholder organisation, namely, Regional Advisory Councils (RACs), that included fisheries representatives, NGOs and other interest groups (Linke et al. 2011). The establishment of these bodies, which give recommendations on fisheries management issues to the EU Commission, marked a new era, challenging the traditional top-down management structure of the CFP. However, while RACs have contributed significantly to a more participatory and inclusive fisheries governance in the EU, authors such as Long (2010: 294) observe that 'the impact so far of the RACs on decision-making within the CFP is less striking than their organisational structure and continues to be the subject of ongoing debate'. Overall the establishment of RACs can be seen as a substantial shift towards stakeholder involvement and potentially even a partially delegated management responsibility to the industry 
or other actors - aspects that have been more vividly discussed in the context of the new CFP reform in 2012/13 (Hatchard and Gray 2014; Nielsen et al. 2015). However, both the RACs' organisational design within the current CFP structure as well as the interactive processes occurring (e.g. in the Baltic RAC) heavily impact on their role and function in future CFP systems. They still have to show how they can deliver future progress and consolidate their role as responsible actors in the transformation of fisheries management towards new approaches of co-management characterised by a new burden of proof regime and sharing of power and responsibility (Linke and Bruckmeier 2015; Linke and Jentoft 2013, 2014).

\subsubsection{Eutrophication}

Eutrophication management at the regional Baltic Sea level is also highly, if not exclusively, science based, however not via an EU centralised policy as for fisheries but through a more informal regional institutional arrangement. The interplay between science and policymaking has been established via a specifically developed decision-support system called 'NEST' with HELCOM as the responsible management agency (Wulff et al. 2007) and with links to various EU directives (see below). As described in more detail by Karlsson et al. (2016) and Linke et al. (2014), scientists at the Baltic Nest Institute developed NEST as a model to provide scientific recommendations for transnational eutrophication management in the Baltic Sea in close cooperation with HELCOM (cf. Wulff et al. 2007), an interplay referred to as the 'NEST-HELCOM nexus' (Linke et al. 2014). This tight science-policy interface, realised through the close interplay between the Baltic Nest Institute and HELCOM, was inscribed in the eutrophication segment of the Baltic Sea Action Plan (BSAP) (HELCOM 2007; Linke et al. 2014) and has been described as a great success in terms of science-policy interaction because the promotion of scientific research resulted in improved knowledge that was, through the decision-support system NEST, made directly applicable to policy- and decision-making on how to mitigate the harmful effects of eutrophication in the Baltic Sea (Johansson et al. 2007). As opposed to the EU fisheries policy (CFP), EU policies applied for mitigating eutrophication (e.g. the Nitrates Directive and the MSFD Descriptor 5 on eutrophication) rest primarily with the member states as does the implementation of agreements and recommendations under regional sea conventions such as the Helsinki Convention. Regarding the latter, the perceived consequences of potential nationally initiated measures led to serious criticism, for example, from farmer organisations (BFFE 2013; LRF 2013), which distorted the previously successful and exclusive interplay between science and policymaking in this area. However, within the EU arena, the MSFD is still under implementation and it remains to be seen if policies fully based on scientific findings will be implemented in full, in order to promote the far from achieved targets for mitigating eutrophication (Karlsson et al. 2016; HELCOM 2013). Similarly, the BSAP-related scientific 
assessments are linked to various EU directives ${ }^{2}$ for a possible harmonisation of aims and objectives (Andersen et al. 2011), but the ultimate success of eutrophication management strongly rests with national implementation plans. It is yet unclear how these will be further implemented (Gilek et al. 2013; Pihlajamäki and Tynkkynen 2011).

The inclusion of stakeholders into processes of management and policymaking with regard to eutrophication in the Baltic Sea is still underdeveloped. While HELCOM has moved from an observer strategy to stakeholder dialogue forums, farmers both nationally and internationally have raised their concerns in connection with the most recent HELCOM ministerial declaration in 2013. Farmers want to be more involved and voice their opinions about ecological and scientific as well as socio-economic aspects related to the implementation of the BSAP (BFFE 2013; LRF 2013; see Sect. 8.3.2).

\subsubsection{Invasive Alien Species}

Invasive alien species (IAS) are recognised as one of the most severe threats to marine biodiversity worldwide. Still, management of environmental risks connected with IAS is a new and undeveloped field of environmental governance (cf. Smolarz et al. 2016). Shipping, which primarily via ballast water has been the source of approximately $50 \%$ of nonindigenous species found in the Baltic Sea (Leppäkoski and Laine 2009), is currently the prime focus in attempts to develop regulations to manage IAS risks in the marine environment. At the core of these regulatory developments is the international BWM Convention, ${ }^{3}$ which sets up standards and procedures for the management and control of ships' ballast waters and sediments to prevent the spread of harmful aquatic organisms. However, although the BWM Convention was opened for signatures by the International Maritime Organization (IMO) in 2004, it is not expected to enter into force until 2015-2016 at the earliest due to a slow ratification process in many countries. ${ }^{4}$ Still, substantial efforts have at the same time been made by intergovernmental organisations such as the EU and HELCOM to improve regulations on IAS, as well as to facilitate implementation of the BWM Convention, for example, by providing guidance and science support adapted to the European and Baltic Sea contexts. The EU has recently adopted a regulation on IAS (EU 2014) based on prevention, early warning and rapid response and management, leaving it to member states to establish science-based lists of IAS. Moreover, HELCOM (2014) has drawn up voluntary recommendations for

\footnotetext{
${ }^{2}$ Examples of such EU directives are the Water Framework Directive (WFD), the Marine Strategy Framework Directive (MSFD), the Nitrates Directive and the Urban Wastewater Directive.

${ }^{3}$ International Convention for the Control and Management of Ships' Ballast Water and Sediments; see http://www.imo.org/OurWork/Environment/BallastWaterManagement/Pages/ BWMConvention.aspx

${ }^{4}$ The convention enters into force 12 months after ratification by 30 states, representing $35 \%$ of world merchant shipping tonnage; at the time of writing, in May 2015, 44 states with $32.9 \%$ of the tonnage have done so.
} 
how to safely perform ballast water exchange before entering the Baltic Sea, as well as provide guidance on how to perform risk assessments and monitoring. Various research projects and databases have been initiated at the European and Baltic Sea level to compile inventories of IAS, as well as identify species and shipping practices connected with particularly high levels of environmental risks (HELCOM 2014; Smolarz et al. 2016).

Hence, both management and assessment activities linked to IAS risks in the Baltic Sea are, despite some recent progress, still in need of further development, particularly in order to reach the ambitious objective set by HELCOM in the 2007 Baltic Sea Action Plan of no introduction of IAS from ships. For example, observations of new IAS often still build on incidental reporting, since targeted and coordinated monitoring is often lacking in high-risk areas. In a wider perspective, it has also been argued that management and science support needs to be improved for 'non-shipping' sources of IAS such as aquaculture and that interdependence with other environmental issues such as fisheries, human-induced climate change and eutrophication need to be considered in risk assessments (Smolarz et al. 2016).

Wide stakeholder involvement at the science-policy interface is lacking in the case of IAS. For most stakeholders and the general public, this seems to be due to a widespread lack of interest in the IAS issue and its management, which are seen as rather uncontroversial and straightforward. In contrast, stakeholders associated with the shipping and cargo sector have shown a strong interest in contributing knowledge and opinions as part of negotiations on development and implementation of regulations (Lemke et al. 2010). Negotiations leading up to the 2004 opening of the BWM Convention have been described by IMO as 'complex'. The subsequent rather long ratification process seems to have been influenced by discussions on, for example, technical possibilities and costs of ballast water management. It therefore remains to be seen whether or not these sector-based discussions will improve efficiency and effectiveness of IAS-related management in the Baltic Sea.

\subsubsection{Chemical Pollution}

There are two central spheres for the governance of chemicals in the marine environment within Europe of relevance for the Baltic Sea region: chemicals policy that takes a market perspective and environmental policy that is based on, for example, aquatic parameters which aim to protect health and the environment (Karlsson et al. 2011).

Within the market sphere of chemicals policy, substances have been classified and further regulated in the EU since the 1960s. Over time, a strong risk-based foundation has emerged, implying that unacceptable risks must be proven in comprehensive assessment before risk reduction measures could be motivated. The ultimate manifestation of such a view is the Technical Guidance Document (TGD) of the EU, comprising thousands of pages of instructions for scientific risk assessments (see, e.g., ECB 2003), which is applied by experts in various advisory and 
decision-making bodies. The heavy burden of proof associated with this 'TGD machine' caused a science-policy deadlock in the 1990s, resulting in assessment of less than 100 out of 100,000 substances registered on the EU market (see Karlsson 2006). After lengthy political debates, the EU adopted a new policy for the bulk of industrial substances, namely, the REACH regulation, which is now the central piece of chemical law in the Baltic Sea region today (EC 2006). REACH is EU harmonised and charges industry with the responsibility of registering data on substance properties. The data is to be evaluated on a scientific basis by the European Chemicals Agency (ECHA), which has a strong technical and expert orientation, and competent authorities of individual EU member states, which judge whether or not to suggest risk reduction measures such as authorisation or restrictions. A strong burden of proof still rests with regulators and, consequently, the implementation has been slow (Karlsson 2010). Several other laws, besides REACH, regulate substances in general and more specifically chemical substances in specific products, for example, electric and electronic products (e.g. EC 2003).

The second sphere, environment-oriented policy and law, focuses on specific parameters for, e.g., water quality, as stated in the WFD (EC 2000) and the MSFD (EC 2008). The scientific focus is strong in this sphere as well, but the starting point here is health and the environment rather than market aspects and EAM is, therefore, often applied. Risk assessments - or more commonly, environmental assessments are carried out in a number of settings, e.g., by agencies, universities or international bodies such as HELCOM, the latter also adopting recommendations on, for example, restrictions aimed at parties of the convention. Individual countries, within the general framework set up in law, are then commonly expected (in the case of HELCOM) or charged (in the case of EU) to ensure implementation of different risk management measures, for instance, regulating emissions of substances from various sources.

There are no specific organisations of a participative nature with regard to stakeholders pertaining to the environment or chemical industry. However, some representatives of certain stakeholder groups are invited to and involved in various steps in decision-making procedures regarding both assessment and management issues, more frequently the case in public organisations at the national, EU and international level than in the scientific committees under them. The strong burden of proof that is placed in the public domain has given industry stakeholders a favourable position to delay processes by repeatedly demanding more data.

\subsubsection{Oil Discharges Linked to Marine Transportation}

Oil transportation in the Baltic Sea creates two different kinds of environmental risks, namely, accidental and intentional oil spills (Hassler 2011, 2016). Whereas the former are rare but may have severe negative impacts on local or regional ecological systems or result in major economic loss and social disturbances, the latter consist of the many small acts of pollution that result from operators cleaning tanks 
or flushing machine compartments en voyage without taking proper care of the disposal of oily residuals. Although the governance structures and measures for oil spill control, as well as associated science-policy interactions, differ in many respects with regard to these issue areas, it is clear that marine transportation is generally governed by a relatively straight chain of command via global conventions under the UN agency IMO (Hassler 2016). However, implementation of these global conventions is primarily the responsibility of individual countries through flag and port state control. Hence, in the Baltic Sea, the management of oil spill risks is determined not only by global conventions but also to a large extent by the individual coastal states, as well as intergovernmental organisations such as HELCOM and the EU. Such management measures at the Baltic Sea level include port state control of ship safety and an incentive-based 'no-special-fee' system to promote safe waste delivery and tank cleaning at port, ${ }^{5}$ as well as aerial surveillance of oil spills (Hassler 2016).

The case of oil discharges involves a comparably clear separation of assessment and management activities, where assessment primarily takes the form of monitoring and surveillance of vessel functionality, tanker traffic and illegal discharges. While these regional, subregional and unilateral monitoring activities ${ }^{6}$ appear to be more developed than e.g. in the case of IAS, coordination still constitutes a significant challenge. This is, for example, seen in the uneven number of flight hours reported by different countries in aerial surveillance of oil discharges (Hassler 2016). The assessment and monitoring linked to tanker traffic and oil discharges do not, however, appear to be very influential in management discussions and decisions linked to technical safety requirements such as double hulls, separate ballast tanks, better navigation equipment, etc. These discussions are instead mostly carried out in IMO, the EU, member countries and international shipping organisations such as INTERTANKO (Hassler et al. 2010).

Therefore, stakeholder involvement in shipping is considerable at the international level, where sector organisations both provide important knowledge and try to influence regime outcomes in the directions they prefer. Classification societies and insurance companies also play important roles in the modernisation of oil tanker fleets. However, stakeholder influence and participation, as well as other forms of civil society involvement, are considerably less intensive at lower governance levels in the Baltic Sea region.

\footnotetext{
${ }^{5}$ This is 'a charging system where the cost of reception, handling and disposal of ship-generated wastes, originating from the normal operation of the ship... is included in the harbour fee or otherwise charged to the ship irrespective of whether wastes are delivered or not' (HELCOM recommendation 28E/10, paragraph 1.1).

${ }^{6}$ Examples of monitoring activities linked to oil discharges and tanker safety in the Baltic Sea include the HELCOM AIS (real-time automatic tracking of all larger vessels), air surveillance and hydrographical surveys (Hassler et al. 2010).
} 


\subsubsection{Managing Uncertainties and Stakeholder Disagreements}

\subsubsection{Fisheries}

In EU fisheries governance, disputes and conflicts exist between major stakeholder groups such as fishermen, NGOs, scientists and policymakers about how to manage and/or preserve fish stocks adequately in the Baltic Sea. These conflicts revolve around basic issues such as 'whose knowledge counts' in the debate between conservationists and those who represent fisheries' interests. Stakeholders are often dissatisfied for different reasons with the management process and consider separate aspects of the CFP as the cause for the failure to attain more sustainable fisheries practices in the Baltic Sea. The disagreements can be categorised under two major issues: the accuracy, objectivity and reliability of different types of knowledge about fish stocks (i.e. data uncertainties), and therefore their applicability to decisionmaking, and secondly, how social issues, i.e. the different value perspectives and worldviews of stakeholders and socio-economic and cultural dimensions, shall be addressed in policy and management under the CFP, which has traditionally been exclusively natural science based (Linke and Jentoft 2014).

Uncertainties in fish stock assessments, and associated stakeholder disagreements about how these uncertainties should be treated in management, have been categorised into three main sources (Linke et al. 2014). The first is the classic notion of scientific uncertainty relating to lack of data, natural variability and ecosystem complexity that is creating tensions in the scientific community (e.g. within ICES) about adequacy of data sources and how to present uncertainty while giving advice to management bodies like the EU Commission (Wilson 2009, 123ff). A second site of uncertainty exists at the centre of science-policy interactions: whereas managers and decision-makers usually want clear, quantified advice, for example, in the form of a fishing quota, scientists often like to give more nuanced qualitative assessments, referring, for example, to 'poorly understood stock dynamics', 'problems with estimating discards' or 'changing fishing patterns' (Sellke et al. 2016; Wilson 2009: 125). This issue relates to the basic conceptual problem of how to define the roles of science and policy in practical interactions (see theoretical Sect. 8.2 above) and leads to constant negotiations about how and where to draw the science-policy boundary - both within science (i.e. in ICES) and management, as well as in the wider stakeholder arena. The third aspect of uncertainty relates to problems that emerge when stakeholders interpret scientific assessments differently according to their own interests and blame opposing actors of misunderstanding or misinterpreting science. Such varying interpretations of scientific uncertainty are obvious in negotiations, e.g., within the RACs, where fisheries and NGO representatives often strongly disagree with each other about whether and how the lack of data and insufficient knowledge shall be used to restrict fishing activity according to the precautionary approach of the CFP, to which conservation groups usually adhere (Linke and Jentoft 2013, 2014). 
These three sites of uncertainty and stakeholder disagreement in EU and Baltic fisheries management reveal key challenges of dealing with highly politicised cases of environmental governance inflicted by social and economic values within a classically designed science-policy interface.

\subsubsection{Eutrophication}

Eutrophication and related management objectives to combat it comprise enormous complexities not only in ecosystem functioning but also with respect to a diverse political arena of governments, economic sectors and stakeholder groups affected by strategies to control eutrophication via nutrient reductions. There are ecosystem structures that lead to particular environmental phenomena in the Baltic Sea such as a relatively slow turnover rate of water (approximately 30 years) and nutrient storage and release from sediments. Furthermore, there are indications that large-scale environmental change (so-called regime shifts) can be amplified by, for example, overfishing of cod (Casini et al. 2009). These complexities lead to several complications for science-policy interactions such as long time lags between implementation of management measures and potential positive effects on environmental status. Such time lags open up for a critique of the scientific basis of taken and proposed measures as well as with regard to general complaints over policies for nutrient reductions, since it is uncertain if and when the desired environmental objectives can be reached. Despite the complexity of the natural and social systems linked to eutrophication management in the Baltic Sea, interactions between scientists and policymakers were quite smooth for a period of time, even if serious questions are now being raised by stakeholders (see below). While a controversy existed earlier (mostly between scientists) about which nutrients needed to be primarily controlled to combat eutrophication - nitrogen, phosphorus or both - there is now a general consensus that both nutrients need to be controlled (Conley et al. 2009a).

However, particularly at the national implementation level, discussions are ongoing about which objectives to set and which nutrient reduction measures might be most cost effective (e.g. Elofsson 2010; Gren 2008; LRF 2013). Moreover, so-called engineering approaches to counter eutrophication problems, such as chemical sequestration of phosphorus or artificial oxygenation, are put forward by various actors but are also criticised by most marine scientists as inappropriate to combat large-scale offshore eutrophication in the Baltic Sea (Conley et al. 2009b; Conley 2012). The academic debate regarding whether man-made oxygenation may or may not be a means to reduce eutrophication effects in the Baltic Sea is still not over (cf. Stigebrandt and Kalén 2013; Stigebrandt et al. 2014). Although substantial uncertainties exist regarding eutrophication assessments and advice, as well as about the ways in which management should best distribute the costs of nutrient reductions among Baltic countries and stakeholders within them, lack of data, scientific uncertainty and stakeholder disagreements have, in contrast to fisheries, not yet sparked similar levels of conflict and public controversy about appropriate policies, management objectives and political decisions. 
This situation, with comparably low levels of stakeholder disagreement on eutrophication management during the first part of the BSAP process leading to a decision on country-wise nutrient reduction targets, might be due to largely underdeveloped forums for stakeholder participation and representation in eutrophicationrelated policy and management. However, affected stakeholder groups like farmers are increasingly organising themselves to voice their opinions, concerns and recommendations on nutrient reduction strategies, at a national as well as international level. These farmers' (as one of the most affected economic stakeholder groups) viewpoints involve calls for inclusion of socio-economic assessments in the implementation of the BSAP, as well as initiation of a broader dialogue with society 'that should be designed so that real influence could be exercised without having to take part in numerous scientific and other meetings' (BFFE 2013).

With regard to the initial assessment for the BSAP in 2007 involving the tight and exclusive NEST-HELCOM interaction (see above and Karlsson et al. 2016), Swedish farmers voiced concerns only with respect to the fact that a 'new and previously untested model is used as the basis for a multi-million decision' (LRF 2010). Now the same stakeholder group, as well as its international counterpart, the Baltic Farmers' Forum on Environment (BFFE), criticises current eutrophication management strategies for implementing BSAP in a more forceful and detailed way with respect to (1) the neglect of the internal phosphorus loads from sediments in the Baltic Sea for BSAP, (2) unrealistic estimations of time frames for recovery (cf. Gustafsson et al. 2012) and (3) cost-efficiency issues (BFFE 2013; LRF 2013).

\subsubsection{Invasive Alien Species}

Despite the fact that maritime transportation is nowadays recognised as the main vector of marine IAS (Leppäkoski and Laine 2009; Smolarz et al. 2016), there are numerous uncertainties associated with the identification of other potential pathways, high-risk species and, above all, long-term ecosystem impacts and associated socio-economic consequences. Linked to this is also an interpretative ambiguity related to assessing the consequences of IAS, since a particular introduction of, for example, a fish species could be associated with both negative (e.g. on native species) and positive effects (e.g. on commercial fisheries). Moreover, it has been argued that neither knowledge about probabilities nor about environmental impacts can be made fully clear for IAS (i.e. in line with an ignorance type of risk, cf. Sect. 8.2), since ecosystem outcomes of IAS will always be influenced by context-specific factors such as type and condition of species, location and season of introduction, etc., associated with particular species introduction (e.g. Zavaleta et al. 2001).

Even though IAS is characterised by high levels of scientific uncertainty and interpretative ambiguity, these aspects have not provoked the same level of disagreement and controversy in science and management as, for example, in fisheries (e.g. Lemke et al. 2010; Linke et al. 2014). This does not mean that there have been no disagreements or controversies linked to regulatory developments in the IAS case but rather that such disagreements have had causes other than scientific 
uncertainties about ecosystem impacts and consequences. For example, disagreements on the technical and economic feasibility of various suggested options for ballast water management have been common (cf. Lemke et al. 2010).

In their analysis of IAS management and assessment, Smolarz et al. (2016) conclude that the fundamental uncertainties outlined above are not sufficiently acknowledged, assessed and managed in the Baltic Sea. The authors also point to the general need to substantially improve the knowledge base, as well as procedures for implementing a precautionary and ecosystem-based approach to IAS management. Still, despite these significant challenges, it is possible to observe some initial steps that have been taken to manage ambiguities and uncertainties linked to IAS risks in the Baltic Sea.

First, by commonly defining IAS as '...species whose introduction and spread threatens ecosystems, habitats or species with economic or environmental harm', the interpretative ambiguities seem to have been 'defined away' in what can be seen as a pragmatic and precautionary approach (cf. Smolarz et al. 2016). That is, this definition assumes that all IAS per definition could cause harm.

Second, although uncertainty in the scientific discourse is mainly discussed in terms of a substantial lack of data (e.g. on monitoring of nonindigenous species in particular environments and ecological consequences of these), the development of regulatory frameworks focuses on preventing entry of IAS in the Baltic Sea by requiring, for example, shipowners to manage ballast water safely. It is, however, too early to evaluate the success of these chosen management approaches, since safety regulations are still not fully implemented and several exemptions have been discussed, for example, in HELCOM regarding low-risk shipping routes in the Baltic Sea.

Finally, several scientific projects and risk assessments initiated by, for example, HELCOM and EU research programmes, have addressed uncertainty by attempting to develop strategies for screening and prioritising risks of various species, vectors, areas and routes. HELCOM has since 2008 published a list of harmful species. There is also a prioritised list of 'target' species exhibiting properties leading to high environmental risks (e.g. HELCOM 2014). Such a pragmatic prioritisation strategy clearly has the potential to focus efforts and resources on issues and areas exhibiting high risk. However, concerns have also been raised that an overly strict management focus on known risks may counteract precaution (Smolarz et al. 2016).

Hence, although uncertainties linked to IAS risks and their consequences for management in the Baltic Sea are substantial and seldom fully acknowledged, some rudimentary pragmatic steps for addressing uncertainty have recently been taken. It is of course too early to tell whether or not these approaches for uncertainty management will be sufficient to counteract potential disputes among stakeholders and allow for effective implementation of the global BWM Convention and the recently adopted EU regulation on IAS in the Baltic Sea region. Ultimately, it also remains to be seen if the primary focus on IAS risks connected with shipping is sufficient to reduce the overall environmental risks of introducing IAS from all sources to levels enabling publicly decided targets. 


\subsubsection{Chemical Pollution}

The complex web of policies, laws and stakeholder groups with different ambitions, in combination with deep uncertainties about both exposure conditions and the inherent properties of thousands of substances on the market, results in possible controversies with regard to chemical pollution. Only few substances on the market have been thoroughly assessed with regard to health and environmental risks (Allanou et al. 1999; Gilbert 2011). Moreover, risk assessments are routinely done substance by substance, according to the highly structured TGD (see above), overlooking how substances may interact despite evidence of special effects of exposure to mixtures ('cocktail effects'; see Kortenkamp et al. 2009). All in all, this makes chemical policy more about managing uncertainty than about managing well-studied risks. Lack of knowledge results in that different actors are competing over preferential rights to interpret the incertitude, which consequently leads to politicisation and disagreements, even within so-called impartial expert groups (Eriksson et al. 2010a, b). Such controversies were obvious not least during the setting up of the REACH regulation in the 1990s and 2000s. While the regulation was considered one of the most contested pieces of legislation in the history of the EU (Fisher 2008; Selin 2007), still today, no specific forum exists for dealing with stakeholder disagreements, at least not beyond conventional representation, consultations and meetings.

In the market-oriented sphere of chemicals policy, stakeholder disagreements and conflicts arise along several lines, for example, between proactive and reactive member states and EU institutions and between other stakeholders such as NGOs and business organisations (Eriksson et al. 2010a). The debates centre on the health or environmental impact of a specific substance and what principles should guide decisions under uncertainty. NGOs and some environmentally ambitious member states support the precautionary principle, i.e. to err on the side of safety and allow for basing measures on intrinsic hazardous properties, whereas industrial organisations commonly promote a non-precautionary, solely risk-based approach, in which the burden of proof is placed on the regulator. This means that management measures must be based on proven unacceptable risks. In contrast to fisheries, where opposition to the dominant set-up of science policy comes from a user perspective (fishers' organisations), the science-policy interface in chemicals is criticised more from an environmental point of view.

In the more recent and environment-oriented policy sphere (mentioned in Sect. 8.3.1.4, including MSFD and BSAP), the precautionary principle is often explicitly recognised. Hence, the mere presence of a substance, suspected to be problematic for the environment, commonly motivates requests for preventive measures. This comparatively low burden of proof for public policymakers implies a very different science-policy interface than in the sphere of chemicals policy. However, nowadays some precautionary elements can be found also in the REACH regulation, which allows for decisions on preventive measures, such as authorisation of substances that are toxic or very bioaccumulative and persistent, even if there is uncertainty about exposure conditions. Such precautionary measures in cases of scientific 
uncertainty are the exception rather than the rule in chemicals policy, and traditional requirements of establishing comprehensive risk assessments before restrictions can be decided are strong (cf. Karlsson and Gilek 2016).

In summary, there are clear differences in how uncertainty and disagreements are dealt with (precautionary or not) in the environmental and the market spheres of chemicals policy, respectively. Science-policy interfaces are hence still far from mature and well coordinated and the deep uncertainty in this governance domain is not addressed rationally. In addition, there are no (standing) forums where stakeholders regularly can meet and discuss these issues and how best to handle disagreements.

\subsubsection{Oil Discharges Linked to Marine Transportation}

The short- and long-term ecosystem effects of oil discharges depend on a variety of factors including the season and weather, type and quantity of oil spilled, habitat, type of shoreline as well as the tidal energy and type of waves in the area of the spill (e.g. Rousi and Kankaanpää 2012). Consequently, there is a substantial degree of scientific uncertainty linked to the assessment of ecosystem risks of oil discharges. However, this type of scientific uncertainty on ecosystem impacts is not of substantial importance for assessment-management interactions in this case (Hassler et al. 2010). That oil discharges are dangerous for the marine environment and should be avoided as much as possible within reasonable economic limits is not contested. ${ }^{7}$ The main issues of assessment-management interactions relating to oil spills rather concern (1) what the actual probabilities and prevalence of oil discharges are (i.e. mainly monitoring and surveillance activities) and (2) how the probability, extent and prevalence of oil spills can be reduced through improved technological safety, reductions in human errors and improved management measures to reduce intentional oil discharges. Consequently, compared with risks such as chemical pollution, the risks of oil discharge and uncertainty-related challenges concerning them are not as severe in the context of the Baltic Sea, barring a few exceptions.

First, there is still a lack of aerial and satellite data of intentional oil discharges for monitoring and surveillance purposes in spite of a well-developed system for monitoring of larger vessels through the HELCOM AIS system (Hassler et al. 2010). This uncertainty linked to surveillance and monitoring impedes a comprehensive assessment of the prevalence of oil discharges (especially intentional discharges), as well as complicates attempts to enforce and monitor the efficiency of management strategies (such as the above-mentioned HELCOM no-special-fee system) (Hassler et al. 2010; Hassler 2011).

Second, regarding safety improvements, there is scientific uncertainty linked to issues concerning the feasibility and cost-efficiency of various technical solutions.

\footnotetext{
${ }^{7}$ It can also be argued that the PSSA (particularly sensitive sea area) classification of the Baltic Sea by the IMO shows that there is an agreement (and substantial scientific knowledge) that the Baltic Sea is particularly sensitive to, e.g., oil discharges.
} 
Today, discussions on these management issues appear to mainly take place in rather closed settings, among IMO officials, IMO member countries and representatives from the shipping industry with limited participation from environmental NGOs (Hassler et al. 2010; Hassler 2016).

Finally, the ecological sensitivity of different areas and 'marine crossroads' where incidents are more likely to occur can be comparably easily identified and located. It is, however, more complex to relate these parameters to what we know about the likelihood of human errors. Although clear distinctions between human error on the one hand and technical malfunction on the other can seldom be made, available statistics show that the former tend to still be the most common cause of incidents and accidents (Knudsen and Hassler 2011).

\subsection{Summarising Discussion}

Using the 'uncertainty matrix' presented in Sect. 8.2 with its four idealised states of incomplete knowledge (Fig. 8.2), we can categorise our five cases as belonging to the categories of risk, uncertainty, ambiguity or ignorance (Table 8.1).

Our analysis focused on two main aspects of science-policy interfaces in the five cases: (1) the organisational structures of science-policy interfaces and (2) the management of scientific uncertainties and stakeholder disagreements. This investigation revealed substantial differences in terms of institutional design of assessment-management interactions, as well as in terms of how scientific uncertainty and sociopolitical ambiguity, stakeholder conflicts and controversies are addressed. Whereas, for example, chemical risks are associated with paramount uncertainty, oil discharges are not. Fisheries management on the other hand involves a high degree of sociopolitical ambiguity, whereas in the case of IAS the opposite is true. Finally, oil transportation fits with the more traditional ('technical') risk type. Our analysis also reveals a great deal of variation in societal responses to the cases and that these responses are often motivated by factors other than the actual risk characteristics.

Regarding the organisational structures of science-policy interfaces, we can conclude that different forms of institutions and institutional arrangements have evolved over time. We find these structures relatively well-formalised in the fisheries case (via the EU's CFP system); rather informal and bilaterally developed for combating eutrophication (through the interaction of the 'NEST-HELCOM nexus'); largely underdeveloped in the IAS case, split into different spheres in the chemicals area (environment versus market); and seemingly straightforward in the case of oil transportation (through country surveillance and monitoring). We also see a clear trend in terms of an intensified role of EU cooperation over time as countries are bound to a centralised EU policy in fisheries management (CFP) and various EU directives and strategies in the other cases. However, the role of the EU varies in the five issues. Furthermore, we can identify different forms of dependence on experts across the cases. In fisheries management, a highly institutionalised formal linkage exists between the science advice system (ICES) and the EU Commission 
Table 8.1 Summary of observed assessment-management interactions linked to environmental problems and risks in the Baltic Sea

\begin{tabular}{|c|c|c|c|}
\hline $\begin{array}{l}\text { Environmental risk } \\
\text { case }\end{array}$ & $\begin{array}{l}\text { State of incomplete } \\
\text { knowledge }\end{array}$ & $\begin{array}{l}\text { Organisational } \\
\text { structures of } \\
\text { assessment- } \\
\text { management } \\
\text { interactions }\end{array}$ & $\begin{array}{l}\text { Management of } \\
\text { uncertainty and } \\
\text { stakeholder (SH) } \\
\text { disagreements }\end{array}$ \\
\hline Fisheries & Ambiguity/Uncertainty & $\begin{array}{l}\text { Highly formalised } \\
\text { structures linked to } \\
\text { the EU's CFP; } \\
\text { science-based with } \\
\text { formalised } \\
\text { stakeholder } \\
\text { consultation e.g. } \\
\text { via RACs }\end{array}$ & $\begin{array}{l}\text { Different framings } \\
\text { and perceptions of } \\
\text { risk } \\
\text { (environmental vs. } \\
\text { socio-economic); } \\
\text { controversy } \\
\text { among SH on } \\
\text { dealing with } \\
\text { uncertainty (e.g. in } \\
\text { data, assessment } \\
\text { and interpretation) }\end{array}$ \\
\hline Eutrophication & Uncertainty/Ambiguity & $\begin{array}{l}\text { Strong/exclusive } \\
\text { role of science } \\
\text { advice } \\
\text { (co-production via } \\
\text { NEST-HELCOM); } \\
\text { limited stakeholder } \\
\text { involvement }\end{array}$ & $\begin{array}{l}\text { Science-based } \\
\text { assessment; } \\
\text { diffuse or } \\
\text { instrumental } \\
\text { treatment of } \\
\text { uncertainty; } \\
\text { increasing } \\
\text { disagreements } \\
\text { among SH groups }\end{array}$ \\
\hline $\begin{array}{l}\text { Invasive alien } \\
\text { species }\end{array}$ & Ignorance & $\begin{array}{l}\text { Rather } \\
\text { undeveloped; no } \\
\text { clearly identifiable } \\
\text { stakeholder groups }\end{array}$ & $\begin{array}{l}\text { Science-based risk } \\
\text { assessment; } \\
\text { undeveloped } \\
\text { uncertainty } \\
\text { treatment; no } \\
\text { major controversy }\end{array}$ \\
\hline Chemical pollution & Uncertainty/Ambiguity & $\begin{array}{l}\text { Strict formal } \\
\text { demands on risk } \\
\text { assessments by } \\
\text { public bodies in } \\
\text { chemicals policy, } \\
\text { less so in } \\
\text { environmental } \\
\text { policy; limited } \\
\text { stakeholder } \\
\text { involvement }\end{array}$ & $\begin{array}{l}\text { Science-based } \\
\text { assessment of } \\
\text { risks in some } \\
\text { contexts, } \\
\text { precautionary } \\
\text { approaches in } \\
\text { other; controversy } \\
\text { on how to cope } \\
\text { with deep-rooted } \\
\text { uncertainty; SH } \\
\text { conflicts but not } \\
\text { coordinated }\end{array}$ \\
\hline Oil discharges & Risk & $\begin{array}{l}\text { Focus on } \\
\text { surveillance and } \\
\text { monitoring (IMO } \\
\text { flag \& port state } \\
\text { control) }\end{array}$ & $\begin{array}{l}\text { Science-based } \\
\text { assessment of } \\
\text { risks; focus on } \\
\text { technical safety } \\
\text { analysis, control } \\
\text { \& enforcement }\end{array}$ \\
\hline
\end{tabular}


(policymaking), as a result of a historic path dependency, that in turn causes various forms of institutional inertia (Hegland and Raakjær 2008; Wilson 2009), even though recent developments with the RACs such as the Baltic RAC may gradually change the picture. This path dependency and the resulting inertia of science and policymaking can also be seen in the chemicals case, where the traditional primacy of risk-based approaches (e.g. the 'TDG machine') is strong. This phenomenon cannot be observed to an equal degree either in the case of eutrophication, where the NEST-HELCOM model offered a comparatively new approach of science-policy interaction, or in the emerging domain of IAS, where an institutionalised form of assessment-management interaction is not yet in place.

Furthermore, well-developed institutional structures as they presently exist for EU fisheries management also seem to allow for the establishment of improved deliberative processes, which at least potentially could result in improved analysis of the socio-economic dimensions of the respective domain of marine governance (cf. Linke and Jentoft 2014; Urquhart et al. 2014). However, apart from an incremental 'opening up' of the linear science-policy structures in fisheries, we cannot find such tendencies developed to a similar extent for eutrophication, IAS, chemicals or oil transportation. In the cases of eutrophication, IAS and chemicals, it may also be substantially harder to identify clear groups of actors definable as 'legitimate stakeholders' to be included in the policy system than when one particular group of actors, for example, 'resource users' (fishermen) or oil transporters (shipowners), can be defined as such and often accused of causing problems e.g. by the media. A rather clear identification of legitimate stakeholders, as we see in fisheries management, is not apparent in the cases of eutrophication (where farming only represents one of several important nutrient sources), chemicals (with a complex web of chemical producing and using actors), IAS or oil transportation.

Regarding uncertainties and stakeholder disagreements, the observed assessmentmanagement interactions do not seem to adequately address the key challenges posed by the different states of knowledge as described in Fig. 8.2 and the sociopolitical ambiguities involved. With regard to management responses dealing with different forms of uncertainty and stakeholder conflicts, thorough analyses of the specific risk characteristics are not apparent, i.e. of the social and natural knowledge requirements or of the suitability of different management strategies such as a traditional science-based assessment, a precautionary approach, deliberative methods for stakeholder participation or extended peer review, etc. (see Sect. 8.2 and Fig. 8.2). Instead, all the studied assessment-management interactions can be classified as building primarily on traditional science-based assessments, which are then applied to policy- and decision-making (Table 8.1). We see, however, a number of ongoing changes and developments in each of the cases that illustrate adaptive responses to the key management challenges studied here.

For example, we detect advancing processes of deliberation and stakeholder inclusion in both the science and management sector in the fisheries case, as an attempt to deal with the principal challenges posed by uncertainty in assessments and management, as well as to address conflicts of interests among the key actors. Concerning eutrophication, we can see similar challenges emerging (i.e. stakeholder 
conflicts impacting on current science-policy interactions). However, in the eutrophication case, stakeholder groups are not yet organised to a similar extent as in fisheries management, and this case does not experience protests and debate to a similar degree as the (much older) governance domain of fisheries. In the chemicals case, where conflicts are dispersed among a variety of stakeholders, we find some approaches for applying precaution to handle the paramount uncertainties and ambiguities. With environmental governance linked to oil transportation, we see a case of technical risk management focusing on safety regulations and reducing human errors, including surveillance and monitoring, without any stakeholder conflicts between dominant actors. IAS governance was, contrary to most of the other cases, identified as an area of low public interest and minor stakeholder conflicts. An interesting observation is that EAM was commonly invoked by stakeholders in the IAS case (albeit often with diverging definitions and framings) as an appropriate basis for developing assessments as well as management measures. Such an interest in EAM was apparent in many of the other cases as well. However, while attempts to develop EAM are perhaps most visible in the environment-oriented policies of the chemicals case and in the struggle to cope with interactions between eutrophication on the one hand and fisheries and chemicals on the other, practical conclusions on how to effectively address and integrate EAM in concrete assessmentmanagement interactions (science-policy interfaces) are still largely missing.

Juxtaposing our results to the model of incomplete states of knowledge in the 'uncertainty matrix' presented above and proposed methodological responses (Sect. 8.2), we cannot yet find a variety of alternative approaches that according to Stirling are required when the traditional risk assessment-management approach is inappropriate. Nevertheless, the comparative analysis of our five marine governance cases highlights different stages in the adaptation of such methodological responses to uncertainty, ambiguity and ignorance that may have the potential to 'reveal the intrinsically normative and contestable basis for decisions, and the different ways in which our knowledge is incomplete' (Stirling 2007: 312). Such more reflective perspectives on the role of science and/versus policy- and decision-making are important for developments to incorporate all three pillars of EAM - ecological, social and economic sustainability - in the respective management systems.

To summarise, our study shows that assessment-management interactions in general have neither developed in line with theoretical assumptions nor in an always purposeful manner. However, a continuation of the tendencies, trends or advancements discussed here can lead to increasingly coordinated and more effective risk governance policies in all five cases. In addition, the ongoing Europeanisation of marine environmental governance in the Baltic Sea illustrated in other studies (cf. Gilek et al. 2015) could potentially lead to a diminished role for HELCOM, owing to the EU membership of most countries around the Baltic Sea and stronger legislative powers of the EU. This will potentially complement and strengthen the mentioned trends. At the same time, the ongoing regionalisation of environmental governance of the Baltic Sea, as seen, for example, in the EU strategy for the Baltic Sea region or with BS RAC under CFP and more recently also the member states' forum BALTFISH 
(cf. Sellke et al. 2016), may also strengthen the role of HELCOM. HELCOM's BSAP is therefore seen as an instrumental way to implement, for example, the EU's MSFD (Gilek et al. 2015). If so, both the EU and HELCOM could become more important for Baltic Sea environmental governance in the future. This might, however, not be an identical outcome for all cases. It remains to be seen how these diverse, but potentially mutually supportive, processes will influence science-policy interfaces linked to the governance of the Baltic Sea environment. Some conclusions and recommendations from the present study are nonetheless highlighted in the following section.

\subsection{Conclusions and Recommendations}

Our study shows the existence of similarities as well as substantial differences in science-policy interactions among the five cases. Overall the case studies illustrate how the common ideal of natural science-based management is distorted by the practical realities of policy- and political decision-making under conditions of ecosystem complexity, uncertainty, sociopolitical ambiguity and stakeholder disagreements. We therefore argue that it is important to consider two main aspects when aiming to improve the 'governability' (Kooiman and Bavinck 2013) of marine socioecological systems like the Baltic Sea. The first aspect argues for a diversity of knowledge perspectives and suggests a balance between natural science-dominated processes and procedures and more precautionary, participatory governance approaches that take account of social dimensions and stakeholder's knowledge contributions (cf. Linke and Jentoft 2014).

The second aspect regards maintaining a balance between the ideals of adopting holistic governance approaches such as EAM and consideration of contextdependent requirements of specific societal sectors, environmental problems and risks (e.g. linked multiple policy objectives, risk types and different states of knowledge and sociopolitical dimensions).

From our analysis, we identify five key issues and challenges that, if adequately addressed, may improve assessment-management interactions, facilitate the implementation of EAM and thus finally improve environmental governance:

1. The organisational structures of science-policy interfaces need to allow for more effective, i.e. timely and context- and place-dependent, interaction between assessment activities and management responses, while simultaneously opening possibilities of distributing power, proof and responsibility to relevant actor groups, all of which would be in line with EAM. This would imply a regional and ecosystem basis of assessment-management interactions capable of addressing prioritised knowledge gaps and developing regional knowledge management and monitoring to strengthen region-based scientific advice.

2. The integration of different forms and states of (incomplete) knowledge is currently undeveloped in assessment and advice to policy- and decision-making. 
This reduces possibilities of addressing the social dimension of sustainable development as well as interdependencies among environmental issues. Knowledge inclusion is therefore a topic that could potentially help to harmonise and democratise policy- and decision-making, as well as contribute to identifying and reducing existing blind knowledge spots.

3. Stakeholder participation and deliberation also require more careful consideration, especially in some of the cases, since the incorporation of practitioner's perspectives and local knowledge in assessments as well as stakeholder deliberation in management are vital for the successful implementation of EAM. How to arrange this in an effective, meaningful and purposeful manner in each case, however, needs to be further studied.

4. We also feel that there is substantial room for improvement with regard to coping with scientific uncertainty and stakeholder disagreements in both assessment and management. We conclude that there are examples of science-based precautionary approaches and methods but that a comprehensive and coherent strategy for addressing uncertainty and disagreements is often lacking. Both the institutional designs of the investigated science-policy interfaces as well as the processes of stakeholder interaction need to be adapted to meet the intentions of 'good' environmental governance as laid down in various EU principles (e.g. in the CFP, EC 2002).

5. Despite the commonly expressed idea of a clear separation between assessment and management, the studied science-policy interactions appear often rather diffuse and politicised. This lack of transparency and reflection about the practical realities of science-policy interactions and how they evolve and are constructed may mislead both political decision-makers and the public and thus potentially hamper effective management progress. As it is unavoidable that the spheres of science and policy are blurred, it is even more important to be transparent about points of departures, underlying values, methodological choices and approaches used in assessment and management related to environmental governance. Furthermore, improved communication about the internal processes of science and policymaking and their interlinkages ('co-production') is similarly important to counteract existing governance deficits.

Acknowledgements This chapter draws on results from the research programme 'Environmental Risk Governance of the Baltic Sea' (2009-2015, Michael Gilek, programme coordinator), which involved research teams from Södertörn University in Sweden, Åbo Akademi University in Finland, Dialogik/Stuttgart University in Germany and Gdansk University in Poland. The funding came from the Foundation for Baltic and East European Studies and the European Community's Seventh Framework Programme (2007-2013) under grant agreement no. 217246 made with the joint Baltic Sea research and development programme BONUS, as well as from the German Federal Ministry of Education and Research (BMBF), the Swedish Environmental Protection Agency, the Swedish Research Council FORMAS, the Polish Ministry of Science and Higher Education and the Academy of Finland. SL also acknowledges funding from the Swedish Research Council and Riksbankens Jubileumsfond. We wish to express our warmest thanks to these institutions for enabling us to conduct this research, to all participants in the research programme that directly or indirectly provided useful input and to all informants sharing their experiences, as well as to two reviewers for their constructive comments on an earlier version of the chapter. 
Open Access This chapter is distributed under the terms of the Creative Commons AttributionNoncommercial 2.5 License (http://creativecommons.org/licenses/by-nc/2.5/) which permits any noncommercial use, distribution, and reproduction in any medium, provided the original author(s) and source are credited.

The images or other third party material in this chapter are included in the work's Creative Commons license, unless indicated otherwise in the credit line; if such material is not included in the work's Creative Commons license and the respective action is not permitted by statutory regulation, users will need to obtain permission from the license holder to duplicate, adapt or reproduce the material.

\section{References}

Allanou R, Hansen BG, van der Bilt Y (1999) Public availability of data on EU high production volume chemicals. European Commission, European Chemicals Bureau, Ispra

Andersen JH, Axe P, Backer H, Carstensen J, Claussen U, Fleming-Lehtinen V, Järvinen M, Kaartokallio H, Knuuttila S, Korpinen S, Kubiliute S, Laamanen M, Lysiak-Pastuszak E, Martin G, Murray C, Møhlenberg F, Nausch G, Norkko A, Villnäs A (2011) Getting the measure of eutrophication in the Baltic Sea: towards improved assessment principles and methods. Biogeochemistry 106:137-156

Backer H, Leppänen JM, Brusendorff AC, Forsius K, Stankiewicz M, Mehtonen J, Pyhälä M, Laamanen M, Paulomäki H, Vlasov N, Haaranen T (2010) HELCOM Baltic Sea Action Plan a regional programme of measures for the marine environment based on the ecosystem approach. Mar Pollut Bull 60:642-649

Boström M, Grönholm S, Hassler B (2016) The ecosystem approach to management in Baltic Sea governance: towards increased reflexivity? In: Gilek M et al (eds) Environmental governance of the Baltic Sea. Springer, Dordrecht

BFFE (2013) Viewpoints from the farmer organisations around the Baltic Sea to the proposal for the ministerial declaration concerning revised HELCOM Baltic Sea Action Plan (BSAP). Available from: http://www.lrf.se

Bijker WE, Bal R, Hendriks R (2009) The paradox of scientific authority - the role of scientific advice in democracies. MIT Press, Cambridge, MA

Cash DW, Clark WC, Alcock F, Dickson NM, Eckley N, Guston DH, Jäger J, Mitchell RB (2003) Knowledge systems for sustainable development. Proc Natl Acad Sci U S A 100(14):8086-8091

Casini M, Hjelm J, Molinero JC, Lövgren J, Cardinale M, Bartolino V (2009) Trophic cascades promote threshold-like shifts in pelagic marine ecosystems. PNAS 106:197-202

COM (2001) European governance: a white paper, Commission of the European Communities 2001428 final, Brussels

Conley DJ (2012) Save the Baltic Sea. Nature 486:463-464, Comment

Conley DJ, Paerl HW, Howarth RW, Boesch DF, Seitzinger SP, Havens KE, Lancelot C, Likens GE (2009a) Controlling eutrophication: nitrogen and phosphorus. Science 323:1014-1015

Conley DJ, Bonsdorff E, Carstensen J, Destouni G, Gustafsson BG, Hansson LA, Rabalais NN, Voss M, Zillén L (2009b) Tackling hypoxia in the Baltic Sea: is engineering a solution? Viewpoint. Environ Sci Technol 43:3407-3411

Degnbol D, Wilson DC (2008) Spatial planning on the North Sea: a case of cross-scale linkages. Mar Policy 32:189-200

EC (2000) Directive 2000/60/EC of the European Parliament and of the Council establishing a framework for Community action in the field of water policy. OJ L 327:1-72

EC (2002) Council Regulation (EC) No 2371/2002 on the conservation and sustainable exploitation of fisheries resources under the Common Fisheries Policy. OJ L 358/59

EC (2003) Directive 2002/95/EC of the European Parliament and of the Council on the restriction of the use of certain hazardous substances in electrical and electronic equipment. OJ L $37: 19-23$ 
EC (2006) Regulation (EC) 1907/2006 of the European Parliament and of the Council concerning the Registration, Evaluation, Authorisation and Restriction of Chemicals (REACH). OJ L 396:1-849

EC (2008) Directive 2008/56/EC of the European Parliament and of the Council establishing a framework for community action in the field of marine environmental policy (Marine Strategy Framework Directive). OJ L 164:19-40

ECB (2003) Technical guidance document on risk assessment. Part I-IV. Joint Research Centre, European Commission, Ispra

Elofsson K (2010) Baltic-wide and Swedish nutrient reduction targets. An evaluation of costeffective strategies. Report to the Expert Group of Environmental Studies 2010:2. Ministry of Finance, Stockholm

Eriksson J, Karlsson M, Reuter M (2010a) Technocracy, politicization, and non-involvement: politics of expertise in the European regulation of chemicals. Rev Policy Res 27:167-185

Eriksson J, Karlsson M, Reuter M (2010b) Scientific committees and EU policy: the case of SCHER. In: Eriksson J, Gilek M, Rudén C (eds) Regulating chemical risks: European and global challenges. Springer, Dordrecht

EU (2014) Regulation (EU) 1143/2014 of the European Parliament and of the Council on the prevention and management of the introduction and spread of invasive alien species. OJ L $317: 35-55$

Fisher E (2008) The 'perfect storm' of REACH: charting regulatory controversy in the age of information, sustainable development, and globalization. J Risk Res 11:541-563

Funtowicz SO, Ravetz JR (1993) Science for the post-normal age. Futures 25:739-755

Funtowicz SO, Strand R (2007) Models of science and policy. In: Traavik T, Lim LC (eds) Biosafety first. Tapir, Trondheim, pp 263-278

Garcia SM, Zerbi A, Aliaume C, Do Chi T, Lasserre G (2003) The ecosystem approach to fisheries. Issues, terminology, principles, institutional foundations, implementation and outlook. FAO fisheries technical paper. No. 443. FAO, Rome

Gezelius S (2008) The arrival of modern fisheries management in the North Atlantic: a historical overview. In: Gezelius S, Raakjær J (eds) Making fisheries management work. Springer, Dordrecht, pp 27-40

Gilbert N (2011) Data gaps threaten chemicals safety law. Nature 475:150-151

Gilek M, Hassler B, Jönsson AM, Karlsson M (eds) (2011) Coping with complexity in Baltic Sea risk governance. Spec Issue Int Sci J AMBIO 40(2) doi:10.1007/s 1^3280-010-0122-4

Gilek M, Hassler B, Engkvist F, Kern K (2013) The HELCOM Baltic Sea Action Plan: challenges of implementing an innovative ecosystem approach. In: Henningsen B, Etzold T, Pohl AL (eds) Political state of the region report 2013 - trends and directions in the Baltic Sea region. Baltic Development Forum, Copenhagen, pp 58-61

Gilek M, Karlsson M, Udovyk O, Linke S (2015) Science and policy in the governance of Europe's marine environment - the impact of Europeanization, regionalization and the ecosystem approach to management. In: Gilek M, Kern K (eds) Governing Europe's marine environment. Europeanization of regional seas or regionalization of EU policies? Ashgate Publishing, Farnham

Gilek M, Karlsson M, Linke S, Smolarz K (2016) Environmental governance of the Baltic Sea identifying key challenges, research topics and analytical approaches. In: Gilek M et al (eds) Environmental governance of the Baltic Sea. Springer, Dordrecht

Gren IM (2008) Costs and benefits from nutrient reductions to the Baltic Sea. The Swedish Environmental Protection Agency. Report 5877

Griffin L (2009) Scales of knowledge: North Sea fisheries governance, the local fisherman and the European scientist. Environ Polit 18:557-575

Gustafsson BG, Schenk F, Blenckner T, Eilola K, Meier M, Müller-Karulis B, Neumann T, RuohoAirola T, Savchuk O, Zorita E (2012) Reconstructing the development of Baltic Sea eutrophication 1850-2006. AMBIO 41:534-548

Hammer M (2015) The ecosystem management approach. Implications for marine governance. In: Gilek M, Kern K (eds) Governing Europe's marine environment. Europeanization of regional seas or regionalization of EU policies? Ashgate Publishing, Farnham 
Hatchard J, Gray T (2014) From RACs to advisory councils: lessons from North Sea discourse for the 2014 reform of the European Common Fisheries Policy. Mar Policy 47:87-93

Hassler B (2011) Accidental versus operational oil spills from shipping in the Baltic Sea - risk governance and management strategies. AMBIO 40:170-178

Hassler B (2016) Oil spills from shipping: a case study of the governance of accidental hazards and intentional pollution in the Baltic Sea. In: Gilek M et al (eds) Environmental governance of the Baltic Sea. Springer, Dordrecht

Hassler B, Söderström S, Lepoša N (2010) Marine oil transportations in the Baltic Sea area. Deliverable 6 within the RISKGOV project. Available from: http://www.sh.se/riskgov

Hegland T, Raakjær J (2008) Recovery plans and the balancing of fishing capacity and fishing possibilities: path dependence in the Common Fisheries Policy. In: Gezelius S, Raakjær J (eds) Making fisheries management work. Springer, Dordrecht, pp 131-159

HELCOM (2007) HELCOM Baltic Sea Action Plan. Helsinki Commission, Helsinki

HELCOM (2010) Ecosystem health of the Baltic Sea 2003-2007: HELCOM initial holistic assessment. Baltic Sea Environmental Proceedings No. 122

HELCOM (2013) Approaches and methods for eutrophication target setting in the Baltic Sea region. Baltic Sea Environment Proceedings No. 133, Helsinki Commission, Helsinki

HELCOM (2014) HELCOM guide to alien species and ballast water management in the Baltic Sea. HELCOM, Baltic Marine Environment Protection Commission, Helskinki

Jasanoff S (ed) (2004) States of knowledge: the co-production of science and social order. Routledge, London

Jasanoff S, Wynne B (1998) Science and decision-making. In: Rayner S, Malone EL (eds) Human choice and climate change, vol 1, The societal framework. Battelle, Columbus, pp 1-87

Johansson S, Wulff F, Bonsdorff E (2007) The MARE research program 1999-2006: reflections on program management. AMBIO 36:1-4

Karlsson M (2006) The precautionary principle, Swedish chemicals policy and sustainable development. J Risk Res 9:337-360

Karlsson M (2010) The precautionary principle in EU and U.S. chemicals policy: a comparison of industrial chemicals legislation. In: Eriksson J, Gilek M, Rudén C (eds) Regulating chemical risks: European and global challenges. Springer, Dordrecht

Karlsson M, Gilek M, Udovyk O (2011) Governance of complex socio-environmental risks: the case of hazardous chemicals in the Baltic Sea. AMBIO 40:144-157

Karlsson M, Gilek M (2016) Governance of chemicals in the Baltic Sea region: a study of three generations of hazardous substances. In: Gilek M et al (eds) Environmental governance of the Baltic Sea. Springer, Dordrecht

Karlsson M, Gilek M, Lundberg C (2016) Eutrophication and the ecosystem approach to management: a case study of Baltic Sea environmental governance. In: Gilek M et al (eds) Environmental governance of the Baltic Sea. Springer, Dordrecht

Knudsen OF, Hassler B (2011) IMO legislation and its implementation: accident risk, vessel deficiencies and national administrative practices. Mar Policy 35(2):201-207

Kooiman J, Bavinck M (2013) Theorizing governability - the interactive governance perspective. In: Bavinck M, Chuenpagdee R, Jentoft S, Kooiman J (eds) Governability of fisheries and aquaculture: theory and applications. Springer, Dordrecht

Kortenkamp A, Backhaus T, Faust M (2009) State of the art report on mixture toxicity. Final report of a project on mixture toxicology and ecotoxicology commissioned by the European Commission, DG Environment

Lemke P, Smolarz K, Zgrundo A, Wolowicz M (2010) Biodiversity with regard to alien species in the Baltic Sea region. RISKGOV report to BONUS EEIG Programme; University of Gdansk, Institute of Oceanography, Gdynia

Leppäkoski E, Laine AO (2009) Alien species. In: Zweifel UL, Laamanen M (eds) Biodiversity in the Baltic Sea. An integrated thematic assessment on biodiversity and nature conservation in the Baltic Sea. Baltic Sea Environmental Proceedings No. 116B. HELCOM - Baltic Marine Environment Protection Commission, Helskinki, pp 119-124 
Lidskog R (2014) Representing and regulating nature: boundary organisations, portable representations, and the science-policy interface. Environ Polit 23:670-687

Linke S, Bruckmeier K (2015) Co-management in fisheries - experiences and changing approaches in Europe. Ocean Coast Manag 104:170-181

Linke S, Jentoft S (2013) A communicative turnaround: shifting the burden of proof in European fisheries governance. Mar Policy 38:337-345

Linke S, Jentoft S (2014) Exploring the phronetic dimension of stakeholders knowledge in EU fisheries governance. Mar Policy 47:153-161

Linke S, Dreyer M, Sellke P (2011) The Regional Advisory Councils: what is their potential to incorporate stakeholder knowledge into fisheries governance? AMBIO 40:133-143

Linke S, Gilek M, Karlsson M, Udovyk O (2014) Unravelling science-policy interactions in environmental risk governance of the Baltic Sea: comparing fisheries and eutrophication. J Risk Res 17(4):505-523

Long R (2010) The role of Regional Advisory Councils in the European Common Fisheries Policy: legal constraints and future options. Int J Mar Coast Law 25:289-46

LRF (2010) Synpunkter från LRF på Slutrapport av Naturvårdsverkets regeringsuppdrag 17 i regleringsbrev för 2008: Förslag till nationella åtgärder enligt Baltic Sea Action Plan (BSAP) (in Swedish). [Opinions from LRF on the final report of the Swedish Environmental Protection Agency's government report 17/2008: Recommendations for national measures according to Baltic Sea Action Plan]

LRF (2013) Hur återställer vi Östersjön? Effektivare strategier mot ett mindre övergött hav (in Swedish). Lantbrukarnas Riksförbund, Stockholm

Nielsen KN, Holm P (2008) The TAC machine: on the institutionalization of sustainable fisheries resource management. In: Nielsen KN (ed) Science|Politics: boundary construction in mandated science - the case of ICES' advice on fisheries management. PhD dissertation, University of Troms $\emptyset$

Nielsen KN, Holm P, Aschan M (2015) Results based management in fisheries: delegating responsibility to resource users. Mar Policy 51:442-451

Pihlajamäki M, Tynkkynen N (eds) (2011) Governing the blue green Baltic Sea - societal challenges of marine eutrophication prevention. FIIA REPORT 31

Renn O (2008) Risk governance: coping with uncertainty in a complex world. Earthscan, London

Rousi H, Kankaanpää H (eds) (2012) The ecological effects of oil spills in the Baltic Sea - the national action plan of Finland. Environmental Administration Guidelines 6en 2012. Finnish Environment Institute, Helsinki

Selin H (2007) Coalition politics and chemicals management in a regulatory ambitious Europe. Glob Environ Polit 7(3):63-93

Sellke P, Dreyer M, Linke S (2016) Fisheries: a case study of Baltic Sea environmental governance. In: Gilek $\mathrm{M}$ et al (eds) Environmental governance of the Baltic Sea. Springer, Dordrecht

Smolarz K, Biskup P, Zgrundo A (2016) Biological invasions: a case study of Baltic Sea environmental governance. In: Gilek $M$ et al (eds) Environmental governance of the Baltic Sea. Springer, Dordrecht

Stigebrandt A, Kalén O (2013) Improving oxygen conditions in the deeper parts of Bornholm Sea by pumped injection of winter water. AMBIO 42:587-595

Stigebrandt A, Rahm L, Viktorsson L, Ödalen M, Hall P, Liljebladh B (2014) A new phosphorus paradigm for the Baltic proper. AMBIO 43:634-643

Stirling A (2007) Risk, precaution and science: towards a more constructive policy debate. EMBO Rep 8:309-315

Stirling A (2008) "Opening up" and "closing down" - power, participation, and pluralism in the social appraisal of technology. Sci Technol Hum Values 33:262-294

Stirling A (2010) Keep it complex. Nature 468:1029-1031

Urquhart J, Acott T, Symes D, Zhao M (eds) (2014) Social issues in sustainable fisheries management. Springer, Dordrecht

Weingart P (1999) Scientific expertise and political accountability: paradoxes of science in politics. Sci Public Policy 26:151-161 
Wilson DC (2009) The paradoxes of transparency: science and the ecosystem approach to fisheries management in Europe. Amsterdam University Press, Amsterdam

Wulff F, Savchuk OP, Sokolov A, Humborg C, Mörth CM (2007) Management options and effects on a marine ecosystem: assessing the future of the Baltic. AMBIO 36:243-249

Zavaleta ES, Hobbs RJ, Mooney HA (2001) Viewing invasive species removal in a wholeecosystem context. Trends Ecol Evol 16:454-459 